Arq. Bras. Med. Vet. Zootec., v.64, n.4, p.804-809, 2012

\title{
Morfometria testicular de cabritos alimentados com óleo de licuri (Syagrus coronata)
}

\author{
[Testicular morphometry of goats fed licury (Syagrus coronata) oil] \\ L.P. Barbosa ${ }^{1}$, R.L. Oliveira ${ }^{2}$, T.M. Silva ${ }^{2}$, I.B. Jesus ${ }^{2}$, A.F. Garcez Neto ${ }^{2}$, A.R. Bagaldo ${ }^{1}$ \\ ${ }^{1}$ Universidade Federal do Recôncavo da Bahia - Cruz das Almas, Ba \\ ${ }^{2}$ Universidade Federal da Bahia - Salvador, Ba
}

\begin{abstract}
RESUMO
Determinou-se o desenvolvimento testicular de caprinos pré-púberes alimentados com óleo de licuri (Syagrus coronata) na dieta. Foram utilizados 19 cabritos 3/4 Boer, recém-desmamados, com média de idade de três meses. Os animais, submetidos a um período de 75 dias de confinamento, receberam alimentação composta por: farelo de milho, farelo de soja, feno picado de tifton 85 e de óleo de licuri com base na matéria seca. Os animais foram distribuídos em quatro grupos: sem lipídio adicional $(\mathrm{n}=5)$; com $1,5 \%$ de óleo de licuri $(n=5)$; com 3,0\% de óleo de licuri $(n=5)$; e com 4,5\% de óleo de licuri $(n=4)$. As avaliações de peso corporal e de biometria testicular foram realizadas quinzenalmente. Após o período de confinamento, os animais foram abatidos para determinação do peso dos testículos, peso dos epidídimos e índice gonadossomático. A adição de óleo de licuri em até 4,5\% na dieta de caprinos pré-púberes não alterou o desenvolvimento testicular com base nas características da biometria e morfometria testicular, indicando que a inclusão de até $4,5 \%$ de óleo de licuri na dieta pode ser utilizada.
\end{abstract}

Palavras-chave: caprino, índice gonadossomático, perímetro escrotal

\begin{abstract}
A trial was carried out to identify the best level of licury (Syagrus coronata) oil in the diet of goats. Nineteen 3/4 Boer male goats at three months of age were kept in individual pens. These animals were submitted to 75 days of confinement. The rations were composed of corn and soybean meal, Tifton 85 chopped hay and levels of licury oil (dry matter base). The animals were arranged in four groups according to the addition of licury oil to the diet: 0.0 (no oil inclusion, $n=5$ ); or addition of $1.5(n=5)$; $3.0(n=5)$; or $4.5 \%$ licury oil. The evaluations of mean body weight and testicular biometry were performed weekly. After confinement, animals were slaughtered and the weight of the left and right testicles, left and right epididymal weight; and gonadosomatic index were determined. The addition of licury oil up to $4.5 \%$ to the diet of prepuberal male goats has not change the testicular development based on its biometrical and morphometrical parameters. It is suggested that licury oil can be added up to $4.5 \%$ to the diet of male goats.
\end{abstract}

Keywords: goat, gonadosomatic index, scrotal perimeter

\section{INTRODUÇÃO}

O uso de gordura e óleos na alimentação de ruminantes confinados, em substituição aos grãos, tem como objetivo aumentar a porcentagem de energia da ração e melhorar o desempenho produtivo e o reprodutivo, bem como reduzir os custos de produção (Fuck, 2006;
Santos, 2008). Dentre as muitas fontes de lipídios está o licuri [Syagrus coronata (Martius) Beccari], palmeira que tem preferência pelas regiões secas e áridas da caatinga e apresenta, nessas regiões, importante papel no potencial socioeconômico para diversas comunidades locais.

Recebido em 6 de abril de 2011

Aceito em 8 de fevereiro de 2012

*Autor para correspondência (corresponding author)

E-mail: larissa@ufrb.edu.br 
A concentração plasmática de colesterol é aumentada em regimes de suplementação lipídica, sendo este precursor da esteroidogênese em todos os tecidos secretores de esteroides. A presença de enzimas esteroidogênicas e quantidades adequadas de substrato (incluindo o colesterol) estão dentre os vários fatores que regulam a síntese e a secreção de hormônios esteroides. Este aumento do colesterol normalmente é devido à necessidade de aumentar a absorção de ácidos graxos armazenados nos quilomícrons e em lipoproteínas de muito baixa densidade no intestino delgado (Niswender e Nett, 1994).

É importante ressaltar que a habilidade reprodutiva dos machos sexualmente maduros depende da capacidade dos testículos em produzir grande número de espermatozoides viáveis e concentrações adequadas de andrógenos para libido e maturação dos órgãos reprodutivos (Gier e Marion, 1969).
Pelo fato de haver poucas informações disponíveis na literatura, este trabalho teve o objetivo de estudar o desenvolvimento testicular de caprinos pré-púberes alimentados com diferentes níveis de óleo de licuri.

\section{MATERIAL E MÉTODOS}

O estudo foi realizado entre outubro e dezembro de 2007. Foram utilizados 19 cabritos 3/4 Boer, recém-desmamados, com média de idade de três meses, os quais foram mantidos em baias individuais de madeira, com piso suspenso, contendo cochos e bebedouros. Os animais receberam as diferentes dietas por um período de 75 dias. Durante o confinamento, duas vezes ao dia, receberam alimentação composta por: farelo de milho, farelo de soja, feno picado de tifton 85 e de óleo de licuri com base na matéria seca (Tab. 1), além de água à vontade.

Tabela 1. Proporção dos ingredientes das dietas utilizadas na alimentação de caprinos 3/4 Boer submetidos a dietas com óleo de licuri

\begin{tabular}{lcccc}
\hline \multicolumn{1}{c}{ Ingrediente } & \multicolumn{4}{c}{ Óleo de licuri (\%MS) } \\
\cline { 2 - 4 } & 0,0 & 1,5 & 3,0 & 4,5 \\
\hline Farelo de milho & 34,1 & 32,3 & 30,4 & 28,7 \\
Farelo de soja & 13,2 & 13,6 & 14,0 & 14,2 \\
Óleo de licuri & 0,0 & 1,5 & 3,0 & 4,5 \\
Premix vitamínico mineral $^{1}$ & 2,6 & 2,6 & 2,6 & 2,6 \\
Feno de tifton 85 & 50,0 & 50,0 & 50,0 & 50,0 \\
\hline
\end{tabular}

${ }^{1}$ Níveis de garantia (por kg em elementos ativos): cálcio 120,00g; fósforo 87,00g; sódio 147,00g; enxofre 18,00g; cobre 590,00mg; cobalto $40,00 \mathrm{mg}$; cromo $20,00 \mathrm{mg}$; ferro $1.800,00 \mathrm{mg}$; iodo $80,00 \mathrm{mg}$; manganês $1.300,00 \mathrm{mg}$; selênio, 15,00mg; zinco 3.800,00mg; molibdênio 300,00mg; flúor máximo 870,00mg; solubilidade do fósforo (P) em ácido cítrico a $2 \%$ mínimo - $95 \%$.

Os animais foram distribuídos aleatoriamente em quatro grupos, sendo que cada grupo foi composto por animais que receberam a seguinte dieta: o primeiro grupo, dieta sem lipídio adicional $-0 \%$ de óleo $(\mathrm{n}=5)$; o segundo grupo, dieta com $1,5 \%$ de óleo de licuri $(\mathrm{n}=5)$; o terceiro grupo, dieta com $3,0 \%$ de óleo de licuri $(\mathrm{n}=5)$; e o quarto grupo, dieta com $4,5 \%$ de óleo de licuri $(n=4)$.

A composição bromatológica das dietas (Tab. 2) foi feita conforme AOAC Association..., (1990) para determinação dos teores de matéria seca (MS), matéria mineral (MM), proteína bruta (PB) e extrato etéreo (EE). As análises para a determinação da fibra em detergente neutro (FDN) e da fibra em detergente ácido (FDA) foram feitas segundo Van Soest et al. (1991). Os carboidratos não fibrosos foram calculados de acordo com Sniffen et al. (1992). No $40^{\circ}$ dia do experimento, foram quantificadas e coletadas fezes e sobras para determinação do consumo e da digestibilidade dos nutrientes. Os teores de nutrientes digestíveis totais (NDT) das dietas foram obtidos por meio da fórmula NDT $=$ PBD + CHTD + 2,25 (EED), em que: PBD = proteína bruta digestível, CHTD $=$ carboidratos totais digestíveis, EED = extrato etéreo digestível (National..., 2001). 
Tabela 2. Composição bromatológica e perfil de ácidos graxos das dietas experimentais utilizadas na alimentação de caprinos 3/4 Boer

\begin{tabular}{|c|c|c|c|c|}
\hline \multirow{2}{*}{ Item } & \multicolumn{4}{|c|}{ Óleo de licuri (\%MS) } \\
\hline & 0,0 & 1,5 & 3,0 & 4,5 \\
\hline Matéria seca $(\%)$ & 89,52 & 89,68 & 89,84 & 90,01 \\
\hline Matéria mineral (\% MS) & 7,54 & 7,53 & 7,53 & 7,53 \\
\hline Proteína bruta (\% MS) & 10,79 & 10,81 & 10,87 & 10,86 \\
\hline Extrato etéreo (\% MS) & 3,37 & 4,78 & 6,20 & 7,61 \\
\hline Fibra em detergente neutro (\% MS) & 43,29 & 43,10 & 42,92 & 42,74 \\
\hline Fibra em detergente ácido (\% MS) & 24,71 & 24,66 & 24,61 & 24,55 \\
\hline Lignina (\% MS) & 4,30 & 4,27 & 4,24 & 4,22 \\
\hline Celulose (\% MS) & 20,41 & 20,39 & 20,37 & 20,33 \\
\hline Hemicelulose (\% MS) & 18,58 & 18,44 & 18,31 & 18,19 \\
\hline Carboidratos não fibrosos (\% MS) & 35,03 & 33,77 & 32,48 & 31,47 \\
\hline Nutrientes digestíveis totais (\% MS) & 67,40 & 69,30 & 75,30 & 80,60 \\
\hline \multicolumn{5}{|c|}{ Perfil de ácidos graxos $(\mathrm{g} / 100 \mathrm{~g}$ de óleo $)$} \\
\hline C12:0 & 0,31 & 1,73 & 3,14 & 4,56 \\
\hline C16:0 & 15,73 & 15,55 & 15,38 & 15,19 \\
\hline C18:0 & 2,64 & 2,71 & 2,79 & 2,87 \\
\hline C18:1 n9 & 27,21 & 26,01 & 24,77 & 23,57 \\
\hline C18:2 n9 & 48,23 & 46,72 & 45,21 & 43,69 \\
\hline C18:3 n3 & 2,16 & 2,15 & 2,14 & 2,13 \\
\hline Outros & 3,71 & 4,79 & 5,89 & 6,96 \\
\hline $\mathrm{AGCM}^{1}$ & 17,21 & 19,53 & 21,85 & 24,16 \\
\hline $\mathrm{AGCL}^{2}$ & 82,79 & 80,47 & 78,15 & 75,84 \\
\hline Saturados & 19,76 & 22,14 & 24,54 & 26,92 \\
\hline Insaturados & 80,24 & 77,86 & 75,45 & 73,08 \\
\hline
\end{tabular}

MS: matéria seca; AGCM: ácidos graxos de cadeia média; AGCL: ácidos graxos de cadeia longa.

Os animais foram pesados quinzenalmente, em balança aferida, munida de brete de madeira para contenção. As mensurações de biometria testicular foram realizadas quinzenalmente, até o término do período experimental, por meio do perímetro escrotal, da largura e do comprimento testicular. O perímetro escrotal foi mensurado com fita métrica graduada, a qual foi posicionada na região mais larga do escroto com os testículos tracionados para baixo. O paquímetro foi utilizado para as mensurações do comprimento e da largura testicular.

Após o período de confinamento, os animais foram abatidos em frigorífico, sob Inspeção Federal. O abate foi realizado 24 horas após dieta hídrica dos animais, conforme preconiza legislação específica para matadouro-frigorífico, sendo realizada a pesagem para determinação do peso corporal ao abate. Os animais foram identificados e marcados por tratamento, ao chegarem à linha de abate, onde foram insensibilizados, seguindo-se a sangria, esfola, evisceração e toalete.

Os testículos foram retirados da carcaça, dissecados para determinação dos pesos testiculares direito e esquerdo, pesos epididimários direito e esquerdo, e, posteriormente, foi calculado o índice gonadossomático (IGS) dos animais, por meio da soma do peso de ambos os testículos, dividida pelo peso corporal do animal, sendo referenciado em porcentagem.

Foi utilizado um delineamento inteiramente ao acaso, bem como a análise de regressão, adotando-se a significância de 5\%.

\section{RESULTADOS E DISCUSSÃO}

Não houve diferença $(\mathrm{P}>0,05)$ entre tratamentos quanto às características de biometria testicular avaliadas, incluindo perímetro escrotal, comprimento e largura testicular (Tab. 3). 
Morfometria testicular...

Tabela 3. Biometria testicular de cabritos mestiços da raça Boer alimentados com óleo de licuri

\begin{tabular}{|c|c|c|c|c|c|}
\hline \multirow{2}{*}{ Característica } & \multicolumn{4}{|c|}{ Óleo de licuri (\% MS) } & \multirow{2}{*}{ EPM } \\
\hline & 0,0 & 1,5 & 3,0 & 4,5 & \\
\hline PE (cm) & 16,34 & 15,12 & 14,54 & 14,30 & 1,60 \\
\hline CTE $(\mathrm{cm})$ & 4,26 & 4,10 & 3,74 & 3,60 & 0,48 \\
\hline $\mathrm{CTD}(\mathrm{cm})$ & 4,34 & 4,10 & 3,72 & 3,62 & 0,45 \\
\hline LTE (cm) & 3,14 & 2,94 & 2,74 & 2,60 & 0,36 \\
\hline LTD (cm) & 3,10 & 2,84 & 2,68 & 2,57 & 0,35 \\
\hline
\end{tabular}

$\mathrm{PE}=$ perímetro escrotal, $\mathrm{CTE}=$ comprimento do testículo esquerdo, $\mathrm{CTD}=$ comprimento do testículo direito, LTE=largura do testículo esquerdo, LTD=largura do testículo direito. EPM: erro-padrão da média.

Fuck (2006), ao trabalhar com caprinos das raças Boer e Anglonubiana com 12 meses de idade, tratados ou não com grão de linhaça na dieta, observou valores de perímetro escrotal de $23,67 \mathrm{~cm}$ e de $24,33 \mathrm{~cm}$, respectivamente. Esses resultados são mais altos que os encontrados neste estudo, o que é justificado pela maior idade dos animais, porém não foi encontrado efeito da adição de óleo na dieta no maior desenvolvimento testicular dos animais, o que corrobora os resultados encontrados no presente trabalho.

Medeiros (2005), ao trabalhar com ovinos mestiços adultos tratados com e sem farelo de castanha de caju na dieta (fonte de lipídios), obteve valores de perímetro escrotal de $30,38 \mathrm{~cm}$ e $31,16 \mathrm{~cm}$, respectivamente, mostrando também a não influência da adição de lipídios na dieta no desenvolvimento testicular dos animais.

Valores semelhantes para largura testicular também foram encontrados por Oliveira (2006), de $2,6 \mathrm{~cm}$ e $2,9 \mathrm{~cm}$, para o testículo direito e o esquerdo, respectivamente. A largura testicular está semelhante aos dados obtidos por Moura et al. (2008), em ovinos da raça Santa Inês aos 18 meses, de $3,03 \mathrm{~cm}$.
De acordo com Fuck (2006), a inclusão de 9,5 \% de grãos de linhaça na matéria seca de caprinos não influenciou o desenvolvimento e a histomorfometria testicular, a espermatogênese, os níveis sanguíneos de testosterona e a taxa de prenhez de fêmeas cobertas por estes reprodutores.

Não houve diferença $(\mathrm{P}>0,05)$ entre tratamentos quanto aos pesos corporal, testicular e epididimário (Tab. 4). Os valores equivalentes de peso corporal dos animais nos quatro grupos mostram que a quantidade de lipídio adicionada à dieta, provavelmente, não foi suficiente para diminuir o consumo de matéria seca, mesmo com a porcentagem total de $7,5 \%$ de lipídios na MS no grupo com 4,5\% de adição de óleo de licuri (Tab. 2), porcentagem considerada acima do recomendado para ruminantes. Medeiros (2005) afirmou que o uso de farelo de amêndoa da castanha de caju (rico em lipídios), como suplementação alimentar em reprodutores ovinos, também não afetou negativamente $\mathrm{o}$ consumo de matéria seca.

Não houve diferença entre os tratamentos $(\mathrm{P}>0,05)$ quanto ao índice gonadossomático (Fig. 1).

Tabela 4. Pesos corporal, testicular e epididimário de cabritos mestiços da raça Boer alimentados com óleo de licuri

\begin{tabular}{|c|c|c|c|c|c|}
\hline \multirow{2}{*}{ Característica } & \multicolumn{4}{|c|}{ Óleo de licuri (\%M) } & \multirow{2}{*}{ EPM } \\
\hline & 0,0 & 1,5 & 3,0 & 4,5 & \\
\hline $\mathrm{PC}(\mathrm{kg})$ & 15,56 & 15,18 & 14,70 & 13,35 & 1,26 \\
\hline PTD (g) & 26,36 & 24,55 & 18,44 & 15,60 & 6,93 \\
\hline PTE (g) & 27,05 & 26,16 & 17,73 & 15,88 & 7,22 \\
\hline $\operatorname{PED}(\mathrm{g})$ & 4,01 & 3,89 & 3,04 & 2,74 & 0,91 \\
\hline PEE (g) & 4,23 & 3,95 & 3,12 & 2,78 & 0,86 \\
\hline
\end{tabular}

$\mathrm{PC}=$ peso corporal, $\mathrm{PTD}=$ peso testicular direito, $\mathrm{PTE}=$ peso testicular esquerdo, $\mathrm{PED}=$ peso epididimário direito, $\mathrm{PEE}=$ peso epididimário esquerdo.

EPM: erro-padrão da média. 


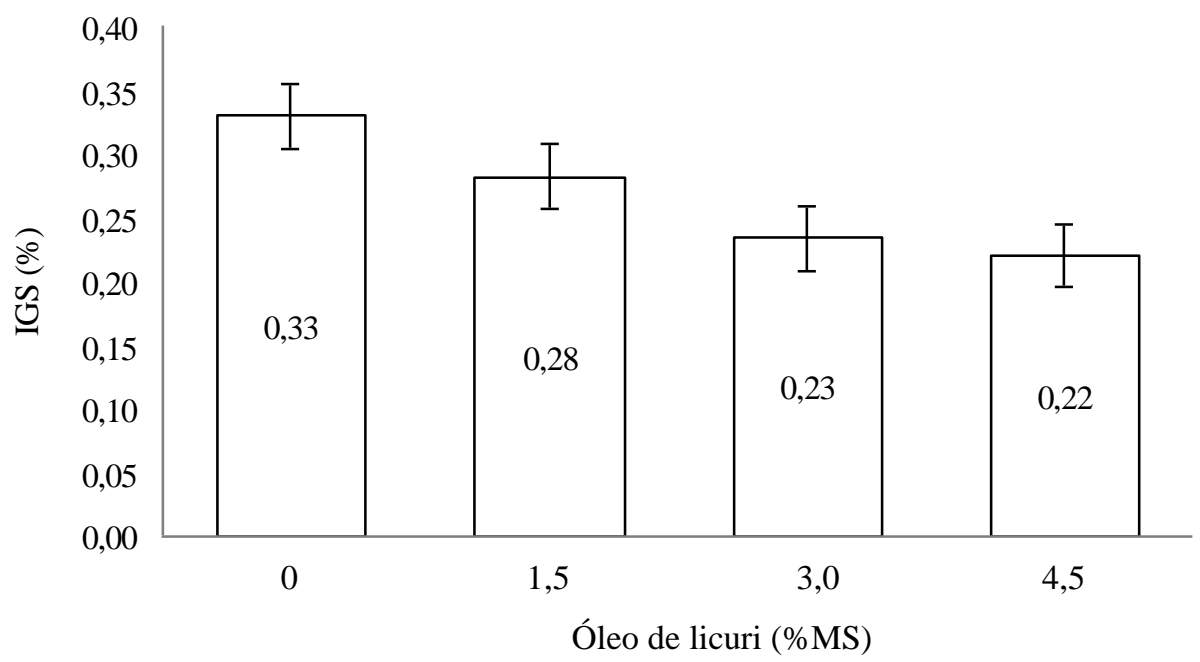

Figura 1. Valores médios e erro-padrão da média do índice gonadossomático de cabritos alimentados com óleo de licuri.

O IGS corresponde à proporção do peso corporal alocada em ambos os testículos, sendo um parâmetro representativo na produção espermatogênica pela alta correlação entre a produção espermática e o peso testicular. O valor médio do índice gonadossomático para todos os animais foi de $0,27 \pm 0,04$, ou seja: $0,27 \%$ do peso corporal foi alocado nos testículos. Valores de índice gonadossomático mais baixos que os do presente estudo foram encontrados por Soares et

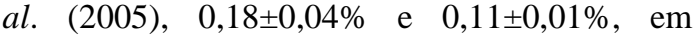
caprinos sem e com restrição alimentar, respectivamente.

\section{CONCLUSÕES}

A adição de óleo de licuri em até 4,5\% na dieta de machos caprinos pré-púberes não alterou o desenvolvimento testicular com base nas características da biometria e morfometria testicular, indicando que inclusões de até 4,5\% de óleo na dieta desses animais podem ser utilizadas.

\section{AGRADECIMENTOS}

À Fundação de Amparo à Pesquisa do Estado da Bahia (FAPESB) e ao Conselho Nacional de Desenvolvimento Científico e Tecnológico $(\mathrm{CNPq})$, pelo financiamento do projeto e fornecimento de bolsa de pesquisa.

\section{REFERÊNCIAS}

ASSOCIATION of official analytical chemists AOAC. Official methods of analysis. Washington:IS. 1990.

FUCK, E.J. Desempenho produtivo $e$ reprodutivo de caprinos machos alimentados com dieta contendo grãos de linhaça. 2006. $76 f$.

Tese (Doutorado) - Universidade Estadual de Maringá, Paraná, 2006.

GIER, H.T.; MARION, G.B. Development of Mammaliam Testis and Genital Ducts. Biol. Reprod., v.1, p.1-23, 1969.

MEDEIROS, M.N. Efeito de dietas com e sem inclusão de farelo de castanha de caju sobre o consumo de matéria seca e parâmetros seminais de ovinos adultos. 41f. Tese (Mestrado em Zootecnia) - Universidade Federal do Ceará, Fortaleza-CE, 2005.

MOURA, J.C.A.; JUCA, A.F.; GUSMÃO, A.L. et al. Ecotextura testicular do carneiro Santa Inês. A Hora Vet., v.162, p.19-22. 2008.

NATIONAL research council - NRC. Nutrients requirements of the dairy cattle. 7.ed. Washington, D.C.: National Academic Press, 2001. 381p. 
NISWENDER, G.D.; NETT, T.R. Corpus luteum and its control in infraprimate species. In: KNOBIL, E.; NEILL, J.D. The physiology of reproduction, New York: Raven Press, 1994. p.781-815.

OLIVEIRA, A.N.; SELAIVE-VILLARROEL, A.B.; MONTE, L.S. et al. Avaliação das características da carcaça de caprinos mestiços Anglo-Nubiano, Boer e caprinos sem padrão racial definido. Cienc. Rural, v.38, p.1073-1077. 2008.

SANTOS, J.E.P. Interação nutrição $e$ reprodução da fêmea bovina. Disponível em: http://www.abz.org.br/publicacoes-tecnicas/ anais-zootec/palestras/23144-Interao-nutrioreproduo-fmea-bovina.html. Acessado em: 20 mar 2008.
SNIFFEN, C.J.; CONNOR, J.D.; VAN SOEST, P.J. A net carbohydrate and protein system for evaluation of cattle diets. II Carbohydrate and protein availability. J. Anim. Sci., v.70, p.35623577, 1992.

SOARES, S.A; BARBOSA, L.P.; NEVES, M.M. et al. Efeito da nutrição sobre o desenvolvimento testicular de caprinos da raça Alpina. In: CONGRESSO BRASILEIRO DE REPRODUÇÃO ANIMAL, 16., 2005, Goiânia. Anais... Goiás: Colégio Brasileiro de Reprodução Animal, 2005.

VAN SOEST, P.J.; ROBERTSON, J.B.; LEWIS, B.A. Methods for dietary fiber, neutral detergent fiber, and nonstarch polyssacharides in relation to animal nutrition. J. Dairy Sci., v.74, p.35833597.1991. (CD-ROM). 